\title{
PARA UMA “RE-VISÃO” DA CRÍTICA LITERÁRIA DA LITERATURA DE AUTORIA FEMININA: O SUBLIME FEMINISTA NO CONTO "AMOR", DE CLARICE LISPECTOR
}

Marcus Vinícius de Oliveira Mitre Rosana Cássia dos Santos

Resumo: Neste artigo pretendemos desenvolver uma análise do conto "Amor", de Clarice Lispector, que compõe a coletânea Laços de Família (1960), intentando contribuir para a reflexão acerca da crítica literária feminista. Ancorada pela noção de sublime feminino, proposta por Barbara Freeman e retomado por Rosana Cássia Kamita nos termos de um sublime feminista, buscamos compreender como, partindo deste conto em particular, Clarice Lispector trabalha nos limites da representação e propõe desafios à crítica, apontando, nos termos de Adrienne Rich, para a necessidade de uma "re-visão" dos moldes literários canônicos, considerados androcêntricos, e apontando, consequentemente, para uma desestabilização da crítica literária tradicional e para a necessidade de construir um outro olhar para a leitura e compreensão da literatura de autoria feminina.

Palavras-chave: Sublime feminista. Clarice Lispector. Crítica literária. Feminismo.

Abstract: In this paper, we intend to develop an analysis of the short story "Amor (Love)", by Clarice Lispector, which composes the collection "Laços de Família (Family Ties)" (1960), aiming to contribute to an insight towards the feminist literary criticism. Based in the concept of the feminine sublime, proposed by Barbara Freeman, and resumed by Rosana Cássia Kamita on the terms of the feminist sublime, we make an attempt to understand how, based on this particular short story, Clarice Lispector works on the verge of representation, challenging the critic, indicating, on the terms of Adrienne Rich, the necessity of a "re-vision" of the canonical literary frame, considered androcentric, and indicating, therefore, to a destabilization of the traditional literary criticism and to the demand of creating another perspective over the reading and comprehension of the female literature authorship.

Keywords: Feminist sublime. Clarice Lispector. Literary criticism. Feminism. 


\section{INTRODUÇÃO}

A proposta deste artigo é a de oferecer uma análise do conto "Amor", de Clarice Lispector, que integra a coletânea Laços de Família (1960). Nele, conta-se a história de Ana, uma dona de casa dedicada e preocupada com seus afazeres cotidianos, com o marido, com os filhos e que mora em uma boa casa. Um dia, ao retornar das compras, foi surpreendida no bonde por um cego parado no ponto, que mascava chicletes com muita naturalidade. Isso a despertou para novas sensações e sentimentos. $O$ bonde volta a andar bruscamente e Ana deixa cair as compras, o que faz com que os ovos que ela comprara se quebrem. Ana, com a ajuda dos passageiros recolhe tudo e o bonde segue viagem. A personagem, distraída, acaba perdendo o ponto que a faria retornar para casa e desce próximo ao Jardim Botânico. Entrou no Jardim e ficou toda a tarde observando cada detalhe do local: pássaros, insetos, folhas, flores, terra, etc. De repente, a personagem lembra dos filhos, do marido e do jantar e corre para casa. Nesse retorno, passou a ver os filhos, o marido e o próprio lar de maneira diferente.

Clarice constrói, nesse conto, imagens fortes, que explicitam um movimento de fronteira, de algo que escapa à compreensão. Trata, portanto, do compreensível que se 
torna, subitamente, incompreensível. Da ordenação que se converte em desordem e que exige um movimento brusco em direção a uma tentativa de reorganização do mundo para que seja possível novamente tentar compreendêlo, mas cuja compreensão nunca é alcançada totalmente, apontando para uma representação do sentimento do sublime experimentado também pela personagem principal do conto. A personagem se permite olhar ao seu redor e ver os diferentes espaços e pessoas, antes considerados tão familiares, como se nunca os houvesse visto ou conhecido, permitindo ainda que esse estranhamento invadisse a si mesma nesse processo.

Para análise, portanto, deste conto em particular, partimos da perspectiva do sublime feminino, teorizado por Bárbara Freeman (1995) e retomado e discutido por Rosana Cássia Kamita (2016) nos termos de um sublime feminista. Essas releituras do conceito do sublime trazem uma perspectiva interessante, uma vez que apontam para uma noção de instabilidade e de paradoxo. Nas palavras de Kamita, "através do sentimento sublime a arte é sempre impulsionada a repensar seus limites" (2016, p. 05).

Nesse sentido, torna-se clara a necessidade constante de reelaboração de um aporte teórico que consiga dar conta 
de uma literatura que, nos termos de Regina Dalcastagnè, apresenta-se como um "território contestado". Conforme aponta a autora, a literatura brasileira passa de instrumento de afirmação da identidade nacional, característica comum em grande parte da produção literária do século XIX e início do século $X X$, para a apropriação de recursos literários por grupos sociais historicamente marginalizados, até mesmo silenciados, que procuram se expressar e ganhar visibilidade, - que também exige uma nova perspectiva da crítica (DALCASTAGNÈ, 2012).

A proposta, então, é explorar os modos pelos quais Clarice Lispector desafiou com seus escritos a crítica literária de seu tempo e, muito frequentemente, ainda desafia a do nosso próprio ao trabalhar nos limites da representação. Essa análise encontra eco na proposta de Adriene Rich, em especial no texto "Quando da morte acordamos: a escrita como re-visão" (2017) ${ }^{1}$, de que a crítica literária necessita de uma "re-visão" que englobe e legitime a literatura de autoria feminina. A perspectiva adotada por Rich torna-se interessante na medida em que aponta para a desnaturalização de preceitos da crítica e para um constante repensar das categorias analíticas, coadunando-se com o

1 Adrienne Rich publicou o ensaio "When We Dead Awaken: Writing as Re-Vision" em 1972. Foi utilizada aqui a tradução de Susana Bornéo Funck, publicada no livro Traduções da cultura. Perspectivas críticas feministas (1970-2010). 2017. 
que propõe Butler (2013) ao discorrer sobre a crítica em um sentido lato. O espaço ocupado pela autoria feminina se dá ao longo do tempo, com nuanças próprias de determinados períodos, e o registro dessa participação ocorre, ainda que de forma frágil e precária, mesmo em séculos passados ${ }^{2}$. No entanto, cumpre pensar não apenas na existência de escritoras e publicação de suas obras, mas ainda naquilo que poderíamos chamar de espaço legitimado da literatura, ou seja, aquele que atribui reconhecimento e torna referenciais determinadas contribuições. Um olhar mais acurado para os sumários dos livros de história da literatura brasileira, por exemplo, ou para as obras selecionadas para vestibular, ou ainda a atribuição dos principais prêmios literários revela que esse espaço legitimado da literatura é restritivo e delineia determinados perfis, invisibilizando uma participação mais diversa e plural.

$\mathrm{Na}$ primeira parte deste artigo, se nos afastamos da análise do conto propriamente dita para explorarmos os conceitos de sublime feminino e de sublime feminista, bem como o conceito de crítica, o fazemos no intuito de construir o embasamento de nossa análise, que se dará na seção seguinte, donde retomaremos trechos do conto

2 A esse respeito, saliente-se a publicação de Escritoras Brasileiras do Século XIX (1999), obra em três volumes organizada por Zahidé Muzart e que contou com uma rede de pesquisadoras responsáveis pela escrita de capítulos nos quais se destacavam autoras brasileiras do passado. 
"Amor". Embora a organização textual pareça refletir um espelhamento da teoria no texto literário, ressalte-se que o movimento de análise propriamente dito foi o inverso: a partir da leitura do conto, precisamente pela inquietação provocada por ele, partiu-se em busca dos aportes teóricos que auxiliavam na sua compreensão e que utilizamos nesse artigo. Se explicamos, portanto, a teoria em primeiro lugar, é apenas por uma questão necessária para facilitar a compreensão da análise que propomos.

\section{EM BUSCA DE NOVOS FUNDAMENTOS PARA A CRÍTICA DA LITERATURA DE AUTORIA FEMININA}

Pode-se dizer que a literatura de autoria feminina ainda propõe desafios à crítica literária tradicional, não obstante os esforços de alguns estudiosos como Adrienne Rich, Hélène Cixous, Júlia Kristeva, Toril Moi, Teresa de Lauretis e Judith Butler, no contexto internacional, e Regina Dalcastagné, Berenice Bento, Denilson Lopes, Guacira Lopes Louro, Carlos Figari, no contexto brasileiro. Estas autoras e autores, apenas para citar alguns, têm desvelado que as bases androcêntricas e normalizadoras da sociedade se refletem na elaboração de padrões utilizados na teoria e na crítica de arte, incluindo aí a crítica literária, padrões esses que não conseguem abarcar uma arte que traz novas 
perspectivas, um novo olhar para e sobre o mundo. Como aponta Adrienne Rich,

para quem escreve, e neste momento para a mulher escritora em particular, há o desafio e a promessa de uma geografia psíquica completamente nova a ser explorada. Mas há, também, um difícil e perigoso caminhar sobre o gelo, na tentativa de encontrar uma linguagem e imagens para uma nova consciência, com pouco passado para nos apoiar. (RICH, 2007, p. 67)

Em outras palavras, a emergência das mulheres na literatura e sua difícil consolidação no campo literário se devem, como veremos, muitas vezes, a aportes teóricos e críticos que não conseguem abarcar literaturas que trazem novas visões sobre o mundo. Essas questões têm sido debatidas há tempos e, de forma mais sistematizada, desde Virginia Woolf, em especial em Um teto todo seu (1985), evidenciando o distanciamento das mulheres do espaço público, seus papéis socialmente marcados pelos serviços voltados ao lar e aos cuidados da família, além da pouca instrução formal recebida por elas, o que dificultava ainda mais que pudessem se tornar escritoras. É importante ressaltar que esta visão excludente se torna ainda mais grave à medida que se considere as mulheres pelo prisma racial, social, etário, por exemplo. Ou seja, muitas delas 
se mantinham responsáveis pelos trabalhos domésticos, acumulando-os com funções mal remuneradas em busca de seu sustento e, muitas vezes, de sua família também.

Assim, ao se tratar de autoria feminina é necessário contextualizar essa participação na literatura na tentativa de se compreender que o espaço literário era interdito ou quase inacessível às mulheres pela própria estruturação de nossa sociedade. Para que se tornassem escritoras, vários fatores deveriam convergir: ter nascido em uma família com boas condições econômicas, que lhes proporcionasse acesso à educação; manter esse padrão social e ter tempo para a escrita; e que seus escritos fossem considerados. Esse último é um aspecto mais sutil e subjetivo, preponderante no passado literário, para as escritoras que adentravam esse território eminentemente masculino. Muitas escritoras acabavam por adotar pseudônimos para publicarem, e então muitas hipóteses poderiam ser consideradas para tentar explicar essa decisão. É possível inferir que desejavam, por exemplo, "preservar" o nome da família ou evitar a exposição às críticas negativas que viessem a receber ou ainda para terem uma liberdade maior ao tratar de determinados temas. Um exemplo é o da escritora catarinense Ana Luísa de Azevedo Castro (1823-1869), que 
ainda no século XIX publicou o romance $D$. Narcisa de Villar: Legenda do tempo colonial (1859) utilizando o pseudônimo Indígena do Ipiranga. Trata-se de um romance com tintas góticas, no qual a personagem D. Narcisa se insurge contra a tirania de seus três irmãos que querem obrigá-la a um casamento arranjado por interesses e assume uma fuga romântica com o indígena Leonardo. A autora trata do "castigo" recebido por D. Narcisa, ao ser assassinada por seu gesto de rebeldia, em um dos primeiros registros de feminicídio de nossa história da literatura brasileira.

Além desse recurso ao uso do pseudônimo, outros eram utilizados, como a apresentação do livro por um escritor ou intelectual reconhecido da época, para "atestar" alguma qualidade literária ao texto. Nesse sentido, é interessante observar o prólogo de João Ribeiro ao livro Marmores (1895), da poetisa Francisca Julia da Silva (1871-1920) ao exaltar a publicação: "Nunca pensei eu que me coubesse algum dia tarefa tão difficil e tão ditosa"; e também em seguida ao fazer uma mea culpa sobre uma manifestação crítica passada, a qual: "[...] havia-me perfidamente creado a pequenina fama (de resto, indigna de mim) de homem selvagem que só via nas mulheres as aptidões inferiores das cozinheiras" (RIBEIRO, 1895, p. 7). ${ }^{3}$ Por vezes, as próprias escritoras se apresentavam

3 Mantida a grafia original. 
de forma muito humilde, como se pode perceber pelo texto dirigido ao público leitor no já citado romance $D$. Narcisa de Villar: "[...] vou rogar a benevolência daqueles que me lerem como um discípulo que se quer instruir" (CASTRO, 1997, p. 17). ${ }^{4}$ Essas questões apresentadas, contribuem para um olhar retrospectivo da crítica literária em relação à autoria feminina, tributária dessa perspectiva de se considerar essa autoria feminina como secundária, atribuindo-lhe comumente um menor valor.

Com Clarice Lispector, tomando por base a crítica literária contemporânea à escritora, não foi diferente. No ensaio "No raiar de Clarice Lispector" (1977), Antonio Candido direciona uma simpática crítica à escritora por Perto do Coração Selvagem (1943), seu romance de estreia ${ }^{5}$. Porém, a despeito de suas boas intenções, é possível perceber, no texto de Candido, uma certa vagueza ao tratar da obra, que pode ser interpretada como uma incompreensão do acontecimento literário que, naquele momento, o crítico descrevia e apreciava. Conforme ele mesmo aponta:

\footnotetext{
4 A esse respeito, ver o artigo "Artimanhas nas entrelinhas: leitura do paratexto de escritoras do século XIX", de Zahidé Muzart, disponível em https://periodicos.ufsc.br/index.php/travessia/ article/download/17202/15776/53007

5 O artigo de Candido foi publicado primeiramente no jornal Folha da Manhã, em 16 de julho 1944, e, posteriormente, compilado no livro Vários escritos, cuja 1ạ edição é de 1970. Regina Pontieri (1999), em um trecho de um trabalho que citaremos na próxima página, afirma, equivocadamente, que o artigo original foi publicado em 1945.
} 
Raramente é dado encontrar um escritor que, como o Oswald de Andrade de João Miramar, ou o Mário de Andrade de Macunaíma, procura estender o domínio da palavra sobre regiões mais complexas e inexprimíveis, ou fazer da ficção uma forma de conhecimento do mundo e das ideias. Por isso, tive verdadeiro choque ao ler o romance diferente que é Perto do coração selvagem, de Clarice Lispector, escritora até aqui completamente desconhecida para mim. (CANDIDO, 1977, p. 126, grifos nossos)

Ainda que simpática, a crítica de Antonio Candido parece desvelar uma certa impossibilidade de analisar o texto clariceano, na medida em que seus referenciais ainda são masculinos ou, melhor dizendo, androcêntricos, no sentido que Ihe empresta Bourdieu6. Álvaro Lins, por sua vez, no artigo "Romance Lírico", publicado no Correio da Manhã, em 1944, direcionou duras críticas à estreante, recheadas de um teor sexista, acusando a escritora de não ter escrito um romance, mas "pedaços de um grande romance".

A publicação do primeiro romance de Clarice parece, portanto, ter criado uma espécie de "curto-circuito" na crítica literária, apontando para lugares onde a língua portuguesa e a literatura brasileira, até então, não haviam explorado. Como ainda aponta Candido:

6 Cf. A dominação masculina (1998). 
Com efeito, este romance [Perto do Coração Selvagem] é uma tentativa impressionante para levar a nossa língua canhestra a domínios pouco explorados, forçando-a a adaptar-se a um pensamento cheio de mistério, para o qual sentimos que a ficção não é um exercício, ou uma aventura afetiva, mas um instrumento real do espírito, capaz de nos fazer penetrar em alguns dos labirintos mais retorcidos da mente. (CANDIDO, 1977, p. 126)

Ao trabalhar nos limites da representação literária, talvez naquele momento de forma mais ou menos inconsciente por se tratar de ume escritora iniciante, Clarice Lispector inaugurava uma diç̧ão ímpar. E, ainda hoje, pode-se dizer que seus escritos desafiam a crítica e suscitam questões importantes. Como aponta Regina Pontieri ao comentar a recepção do romance $A$ cidade sitiada (1949) por parte dos críticos:

Como seria natural que ocorresse, a crítica dos inícios de carreira de Clarice, nas décadas de 1940 e 1950, ressentia-se de dois tipos de falta: de uma mais ampla visão de conjunto da Obra, por um lado; de um aparato crítico adequado à experiência literária proposta, por outro. Esse último aspecto for apontado por Antonio Candido, referindo-se a Perto do Coração Selvagem, no artigo de jornal de 1945 que posteriormente viriam a constituir o ensaio "No Raiar de Clarice Lispector". Dessas carências se ressentiram não só Milliet, mas Álvaro Lins e Gilda de Mello e Souza, independentemente da acuidade 
crítico-analítica com que abordavam o trabalho da escritora. (PONTIERI, 1999, p. 39)

A falta de um aparato crítico fez com que a crítica brasileira contemporânea a Clarice ficasse impressionada. A escrita "diferente" da autora, como aponta Candido, ganhará, posteriormente, o epíteto de hermética por vários críticos, dentre eles o português João Gaspar Simões, que em 1950 publica uma crítica sobre $A$ Cidade Sitiada no jornal carioca A Manhã. Simões é considerado, segundo Pontieri, um dos primeiros a utilizar o epíteto de hermética para se referir à literatura de Clarice (PONTIERI, 1999, p. 40).

Diante da naturalização da crítica que, como brevemente explicitado acima, não soube "repensar seus limites" ao abordar o texto clariceano, cabe refletirmos sobre o que propõe Judith Butler no ensaio "O que é a crítica? Um ensaio sobre a virtude em Foucault" (2013). A autora afirma que

a prática da crítica não jorra de uma liberdade inata à alma. Ela, antes, forma-se no embate entre uma troca específica entre um conjunto de regras e preceitos (que já estão dados) e uma estilização de atos (que expande e reformula esse conjunto prévio de regras e preceitos). Essa estilização do "eu", em relação às regras, acaba por constituir uma "prática". (BUTLER, 2013, p. 169) 
A crítica, então, precisa sempre repensar seus pressupostos e o empreendimento filosófico de Butler, ao retomar Foucault, trabalha no sentido de desnaturalizar a crítica, intentando compreender como uma gama de discursos operam no sentido de dar uma aparência "natural" a algo que, na realidade, é um construto histórico-social.

Nessa linha de raciocínio, a noção do sublime feminista (KAMITA, 2016) surge, na atualidade, como uma perspectiva que permite uma nova compreensão do fazer literário que acompanhe as mudanças temáticas e formais da literatura, mormente da literatura de autoria feminina, que vêm ganhando espaço, mas ainda é, muitas vezes, considerada menor ou secundária. Nesse sentido, Bárbara Freeman propõe que

o sublime feminino não é nem um modo retórico nem uma categoria estética, mas um domínio da experiência que resiste à categorização, em que o sujeito entra em relação com uma alteridade - social, estética, política, ética, erótica - que é excessiva e irrepresentável. O sublime feminino não é uma estratégia discursiva, uma técnica ou um estilo literário que a escritora inventa, mas sim uma crise em relação à linguagem e à representação que um determinado sujeito sofre. Como tal, é o lugar tanto das experiências afetivas das mulheres quanto de seus encontros com os mecanismos gendrados de poder de meados do século 
XVIII (quando a teoria do sublime tornou-se importante) até o presente, pois responde especificamente às diferentes configurações culturais de opressão, paixão e resistência das mulheres. ${ }^{7}$ (FREEMAN, 1995, p. 2) ${ }^{8}$

É preciso, entretanto, diferenciar o uso tradicional do sublime, que remonta à tradição. Ainda de acordo com Freeman, autores como Adisson, Burke e Kant propõem o sublime como um sentimento cujo traço constitutivo é a noção de espectadorismo, que pressupõe uma atitude passiva do espectador diante do evento/objeto/fenômeno causador do sentimento sublime. Nesse sentido, é perceptível em Kant a ideia de 'excesso que resiste aos seus poderes', donde, nessa perspectiva kantiana, o espectador só sente prazer com o sublime porque está certo que este não pode afetá-lo. Freeman, por sua vez, problematiza e aponta para uma desestabilização dessa noção, defendendo

uma leitura do sublime como uma alegoria da construção do sujeito patriarcal (mas não necessariamente masculino), um eu que mantém suas fronteiras ao subordinar a diferença e ao se apropriar do que o que

7 No original: "The feminine sublime is not a discursive strategy, technique, or literary style the female writer invents, but rather a crisis in relation to language and representation that a certain subject undergoes. As such it is the site both of women's affective experiences and their encounters with the gendered mechanisms of power from the mid-eighteenth century (when the theory of the sublime first came to prominence) to the present, for it responds specifically to the diverse cultural configurations of women's oppression, passion, and resistance."

8 Os excertos de Freeman foram traduzidos por Maria Isabel de Castro Lima. 
se apresenta como o outro, em vez de se identificar com ele. ${ }^{9}$ (FREEMAN, 1995, p. 4)

A autora fala, na esteira desse pensamento, de um "sublime feminino". A leitura de Freeman busca, portanto, aproximar as noções clássicas do sublime e mostrar suas fissuras e seus rompimentos na ficção de mulheres. O conceito de sublime feminino de Freeman será retomado por Kamita, que explora a ideia de um sublime feminista. A ideia do "curto-circuito" utilizado em referência à crítica tempestiva à estreia do romance Perto do coração selvagem (1977) aponta para uma noção de sublime, no sentido destacado pela autora ao retomar Lyotard:

Como aponta Lyotard em Lições Sobre a Analítica do Sublime (1993), psicologicamente falando, o prazer e o desprazer são os responsáveis por pautar a faculdade de julgar, centrando-se, todavia, não no objeto, mas no sujeito, estabelecendo uma relação de tautegoria, na qual o sujeito informa o "espírito" sobre o seu "estado", como um raio, provocando um curto circuito do próprio pensamento. (KAMITA, 2016, p. 104)

O sublime diferencia-se do belo, uma vez que este propõe a instituição de paradigmas para que seja julgado, enquanto o sublime, pelo contrário, propõe o oposto, isto é, questionar

9 No original: "a reading of the sublime as na allegory of the construction of the patriarchal (but not necessary male) subject, a self that maintains its borders by subordinating difference and by appropriating rather than identifying with that which presents itself as other." 
os limites destes paradigmas (KAMITA, 2016, p. 106). Nesse sentido, "O juízo estético sublime expõe a crise, a fratura, em um momento de ruptura com o compreensível, apresenta-se com a marca do excessivo, do absoluto, do infinito" (KAMITA, 2016, p. 106).

A autora ressalta ainda a impossibilidade de uma leitura isolada da literatura de autoria feminina, mas como essa deve ser inserida em um conjunto que questões, como uma postura ética e política. Assim, ela propõe que

compreender a literatura de autoria feminina é, portanto, não se limitar à estreita visão da tradição literária, mas contextualizála observando as relações que mantém com outros textos e as estruturas sociais e culturais que compõem o panorama da época. (KAMITA, 2016, p. 112)

Ao explorar as personagens femininas e sua relação com o mundo, como a personagem Ana no conto "Amor", Clarice Lispector expõe as fissuras no cânone literário e desvela uma nova consciência que se percebe oprimida pela organização da sociedade e pelas normas que a governam. Nesse sentido, a literatura desvela toda uma nova geografia psíquica a ser explorada, como propõe Adrienne Rich. Essa tomada de consciência, portanto, como ainda propõe a autora, raramente se dá de modo tranquilo e indolor. Ela aponta que 
é emocionante viver numa época em que a consciência desperta; mas também pode ser confuso, desorientador e doloroso. O despertar dessa consciência morta ou dormente já afetou a vida de milhões de mulheres, mesmo aquelas que ainda não o perceberam. Também está afetando as vidas dos homens, mesmo daqueles que ignoram seu chamado. (RICH, 2017, p. 67)

A autora enfatiza, justamente, o sentimento paradoxal: o emocionante e doloroso despertar de uma nova consciência, a apresentação de uma nova visão sobre o mundo, que exige uma "re-visão" da escrita e da crítica literária. Nesse sentido, a literatura escrita por mulheres aponta para um movimento de constante reavaliação, direcionando para uma associação possível da literatura escrita por mulheres com o sublime. As mulheres aqui não são mais personagem que "servem como deleite" para os homens (RICH, 2017, p. 68) partindo de uma literatura escrita por eles: as personagens femininas ganham profundida psicológica, expõem-se às tensões com os construtos sociais, com o mundo. Essas proposições coadunam-se com o que propõe Kamita:

O sublime enseja a possibilidade de repensar as categorias de análise e de crítica que são utilizadas a partir de novas possibilidades que se apresentam como informes, ou exemplos a priori, e que exigem alterações 
de princípios e padrões pré-estabelecidos. O paradigma do belo é confrontado pela inquietação do sublime, o belo estabelece as condições de apresentação e recepção da arte, mas não se detém sobre o inesperado, sobre as experimentações. $O$ sublime se situa nesse espaço, entre o prazer da descoberta de algo novo e o desprazer de não conseguir apreendê-lo ou compreendê-lo, reconhecimento de uma arte dinâmica, que subverte constantemente as regras que se lhe deseje imputar. Como anteriormente exposto, a faculdade de apresentação falha diante de uma ideia desconhecida, o que impulsiona o pensamento a situar-se fora dos padrões estabelecidos. (KAMITA, 2016, p. 108)

\section{UMA ANÁLISE DO CONTO “AMOR” DA PERSPECTIVA DO SUBLIME FEMINISTA}

Passando para a análise do conto "Amor" e relacionando-o com o que foi discutido acima, observamos que o narrador procura descrever o sentimento e a reação da personagem Ana, uma dona de casa dedicada e cumpridora de seu papel de esposa, ao se deparar com um cego mascando chiclete:

Foi então que olhou para o homem parado no ponto.

A diferença entre ele e os outros é que ele estava realmente parado. De pé, suas mãos se mantinham avançadas. Era um cego.

O que havia mais que fizesse Ana se aprumar em desconfiança? Alguma coisa 
intranquila estava sucedendo. Então ela viu: o cego mascava chicles... Um homem cego mascava chicles.

Ana ainda teve tempo de pensar por um segundo que os irmãos viriam jantar o coração batia-lhe violento, espaçado. Inclinada, olhava o cego profundamente, como se olha o que não nos vê. Ele mascava goma na escuridão. Sem sofrimento, com os olhos abertos. O movimento da mastigação fazia-o parecer sorrir e de repente deixar de sorrir, sorrir e deixar de sorrir - como se ele a tivesse insultado, Ana olhava-o. E quem a visse teria a impressão de uma mulher com ódio. Mas continuava a olhá-lo, cada vez mais inclinada - o bonde deu uma arrancada súbita jogando-a desprevenida para trás, o pesado saco de tricô despencou-se do colo, ruiu no chão - Ana deu um grito, o condutor deu ordem de parada antes de saber do que se tratava - o bonde estacou, os passageiros olharam assustados. (LISPECTOR, 2016, p. 147-148)

Neste trecho, o despertar brusco da consciência de Ana provoca um sobressalto na personagem. Ana desperta ao ficar frente a frente com a alteridade. Esse despertar dá-se pela confrontação direta com o mundo, que a aproxima do sentimento do sublime. Porém, ao contrário de uma noção do sublime calcada na ideia de espectadorismo, Ana sai modificada da experiência:

Mas os ovos se haviam quebrado no embrulho de jornal. Gemas amarelas e 
viscosas pingavam entre os fios da rede. 0 cego interrompera a mastigação e avançava as mãos inseguras, tentando inutilmente pegar o que acontecia. $\mathrm{O}$ embrulho dos ovos foi jogado fora da rede e, entre os sorrisos dos passageiros e o sinal do condutor, o bonde deu a nova arrancada de partida. (LISPECTOR, 2016, p. 148)

Há aqui uma referência a algo que excede os limites preestabelecidos. A referência aos ovos quebrados, que pingam entre os fios da rede de tricô, trama tecida pacientemente, que aponta para uma ideia de algo que extrapola uma norma pré-construída, um construto cultural que impõe limites. Essa perspectiva fica mais clara na continuação do episódio:

A rede de tricô era áspera entre os dedos, não íntima como quando a tricotara. A rede perdera o sentido e estar num bonde era um fio partido; não sabia o que fazer com as compras no colo. E como uma estranha música, o mundo recomeçava ao redor. 0 mal estava feito. Por quê? Teria esquecido de que havia cegos? A piedade a sufocava, Ana respirava pesadamente. Mesmo as coisas que existiam antes do acontecimento estavam agora de sobreaviso, tinham um ar mais hostil, perecível... O mundo se tornara de novo um mal-estar. Vários anos ruíam, as gemas amarelas escorriam. Expulsa de seus próprios dias, parecia-lhe que as pessoas da rua eram periclitantes, que se mantinham por um mínimo equilíbrio à tona da escuridão 
- e por um momento a falta de sentido deixava-as tão livres que elas não sabiam para onde ir. Perceber uma ausência de lei foi tão súbito que Ana se agarrou ao banco da frente, como se pudesse cair do bonde, como se as coisas pudessem ser revertidas com a mesma calma com que não o eram. (LISPECTOR, 2016, p. 148-149)

Ana perde a familiaridade com o mundo que a circunda através deste despertar da consciência. Ela pondera que "[v]ários anos ruíam" (LISPECTOR, 2016, p. 148), o que aponta para um questionamento da norma, para um ideal de liberdade que assoma em seus devaneios, em que as pessoas estão "tão livres que não sabiam para onde ir" (LISPECTOR, 2016, p. 149). Ana então busca em seus pensamentos retornar para a ordenação corriqueira de seu mundo e se perde em devaneios, passando do ponto em que deveria saltar do bonde:

Ela apaziguara tão bem a vida, cuidara tanto para que esta não explodisse. Mantinha tudo em serena compreensão, separava uma pessoa das outras, as roupas eram claramente feitas para serem usadas e podia-se escolher pelo jornal o filme da noite - tudo feito de modo a que um dia se seguisse ao outro. E um cego mascando goma despedaçava tudo isso. $E$ através da piedade aparecia a Ana uma vida cheia de náusea doce, até a boca.

Só então percebeu que há muito passara do seu ponto de descida. Na fraqueza em que 
estava, tudo a atingia com um susto; desceu do bonde com pernas débeis, olhou em torno de si, segurando a rede suja de ovo. Por um momento não conseguia orientarse. Parecia ter saltado no meio da noite. (LISPECTOR, 2016, p. 149)

A desorientação sentida por Ana aponta para um sentimento sublime que tem como eixo central um papel pretensamente atribuído às mulheres pela sociedade heteronormativa, qual seja, o da organização do mundo, com todos os itens guardados e dispostos em seus devidos lugares. Ana parece questionar esse papel que lhe é atribuído e a falta de um referencial a faz perder-se, desorientar-se. Ana adentra, então, o Jardim Botânico e experimenta um novo mundo:

A vastidão parecia acalmá-la, o silêncio regulava sua respiração. Ela adormecia dentro de si.

De longe via a aleia onde a tarde era clara e redonda. Mas a penumbra dos ramos cobria o atalho.

Ao seu redor havia ruídos serenos, cheiro de árvores, pequenas surpresas entre os cipós. Todo o Jardim triturado pelos instantes já mais apressados da tarde. De onde vinha o meio sonho pelo qual estava rodeada? Como por um zunido de abelhas e aves. Tudo era estranho, suave demais, grande demais. (LISPECTOR, 2016, p. 150)

Essa vastidão do mundo detectada pela personagem pode ser relacionada ao que propõe Kamita ao retomar as 
diferenças entre o colossal e o sublime. Nesse sentido, a autora aponta que

o colossal é o vislumbre de possibilidade de representação do inapresentável, do infinito. O sublime comporta a incomensurabilidade violenta do impacto e que não reside no objeto, mas no sujeito, segundo Derrida, sentimento provocado pela inadequação de várias faculdades e potências. (KAMITA, 2016, p. 109)

Ana procura retomar sua capacidade crítica diante do mundo, adequar suas faculdades e potências. Procura compreender o que lhe acontece, o sentimento íntimo que a provoca e a insta a se desviar do caminho corriqueiro, onde a aguardam a casa, os filhos, o marido. A personagem, pode-se dizer, experimenta o sentimento do sublime: ao mesmo tempo algo que a agrada a repugna e ela identifica "[...] uma vida cheia de náusea doce, até a boca" (LISPECTOR, 2016, p. 149). O narrador do conto recorre a paradoxos para tentar representar o que sente Ana. O sentimento sublime aponta, justamente, para essa relação paradoxal. Nos dizeres de Kamita:

O sublime se situa nesse espaço, entre o prazer da descoberta de algo novo e o desprazer de não conseguir apreendê-lo ou compreendêlo, reconhecimento de uma arte dinâmica, que subverte constantemente as regras que se the deseje imputar. (KAMITA, 2016, p. 109) 
Ao final do conto, Ana retorna para casa, para a velha e familiar organização. Toda aquela vida que ela detectara no Jardim Botânico ficara para trás e ela volta aos seus afazeres domésticos, sem dúvida modificada pela experiência que vivera:

Depois, quando todos foram embora e as crianças já estavam deitadas, ela era uma mulher bruta que olhava pela janela. A cidade estava adormecida e quente. $\mathrm{O}$ que o cego desencadeara caberia nos seus dias? Quantos anos levaria até envelhecer de novo? Qualquer movimento seu e pisaria numa das crianças. Mas com uma maldade de amante, parecia aceitar que da flor saísse o mosquito, que as vitórias-régias boiassem no escuro do lago. $O$ cego pendia entre os frutos do Jardim Botânico. (LISPECTOR, 2016, p. 154-155)

Ana, depois de experimentar uma espécie de amor pelo mundo, torna-se uma mulher bruta, pois parece adquirir uma consciência dolorosa do lugar que lhe é imposto na sociedade, que a cerceia de diversos modos. A experiência do sublime a modificara indelevelmente, de forma que ela passa a (re) considerar sua existência e questionar: "O que o cego desencadeara caberia nos seus dias?" (LISPECTOR, 2016, p. 155).

Assim, ao associar o sublime com uma ruptura ao que é (re)conhecido, modelar ou apreensível, podemos nos 
aproximar da autoria e também da representação literária feminina. Tanto a escritora Clarice Lispector quanto a sua personagem Ana, no conto "Amor", provocam uma fissura ao instituído. A primeira, ensejando o reconhecimento de uma contribuição diferente do perfil de escrita da literatura em geral, e daquele associado às escritoras, em particular. A segunda, ao se deixa abstrair do mundo doméstico e familiar, permitindo-se experimentar diferentes sensações de ser e estar em uma sociedade ainda tão reguladora. No entanto, a sensação sublime não se restringe à fissura que possa provocar, mas ao sentimento de "susto" ou "medo" frente a essa possibilidade. Dessa maneira, a crítica literária, assim como os leitores e as leitoras, se sentiram e ainda se sentem desafiados frente à literatura produzida por Clarice Lispector. Ana pode ser representativa de tantas outras mulheres que desejam mais do que cumprir aquilo que delas se espera, experimentar a sensação da liberdade e o sentimento sublime, sem que o preço para isso seja aquele pago por D. Narcisa de Villar.

\section{CONSIDERAÇÕES FINAIS}

O sublime feminista enseja uma nova possibilidade de repensar a literatura, mormente da literatura de autoria feminina, ao questionar os paradigmas instituídos da 
arte e apontar para a desestabilização de preceitos e de preconceitos que a rondam. Essa nova visão do mundo, segundo Kamita e Freeman, deve ser abordada não pelo mero espectadorismo, mas deve-se buscar uma visão empática e construtiva. Como propõe Kamita, "o outro não precisa ser necessariamente associado ao perigo por ameaçar o já instituído, mas poderá ser visto justamente como possibilidade de uma nova perspectiva, na adoção de uma postura de aceitação e respeito às diferenças" (KAMITA, 2016, p. 115). Assim, a literatura escrita por mulheres indica a necessidade de uma reordenação epistemológica da teoria e da crítica literárias tradicionais, fundada em bases androcêntricas.

Nesse sentido, as críticas contemporâneas a Clarice Lispector, na falta de um aporte teórico que as respaldassem, em alguns momentos se mostraram capazes de reconhecer um novo horizonte que se desenhava pelo texto clariceano; outras vezes resvalaram para a pura incompreensão e até mesmo para um sexismo brutal, que não reconheceu sequer o papel das mulheres como escritoras. No entanto, sua literatura diferente abriu, nos dizeres de Candido, um novo caminho e, a despeito das incompreensões, Clarice se firmou como escritora conhecida e reconhecida, demonstrando toda a força de sua literatura. 


\section{REFERÊNCIAS}

BOURDIEU, Pierre. A dominação masculina - a condição feminina e a violência simbólica. Rio de Janeiro: Bestbolso, 2018.

BUTLER, Judith. O que é a crítica? um ensaio sobre a virtude de Foucault. Tradução de Gustavo H. Dalaqua. Cadernos de Ética e Filosofia Política, n. 22, p. 159-179, 2013.

CANDIDO, Antonio. No raiar de Clarice Lispector. In: CANDIDO, Antonio. Vários Escritos, 1977.

CASTRO, Ana Luísa de Azevedo. D. Narcisa de Villar: Legenda do tempo colonial. Florianópolis: Ed. Mulheres, 1997.

DALCASTAGNÈ, Regina. Um território contestado: literatura brasileira contemporânea e as novas vozes sociais. Revista Iberic@l, n. 2, p. 13-18, 2012.

FREEMAN, Barbara. The feminine sublime: Gender and excess in women's fiction. University of California Press, 1995.

KAMITA, Rosana Cássia. Mulheres e Literatura: Sob a perspectiva do sublime. Cadernos de Literatura Comparada. n. 35, dezembro, 2016. Disponível em: http://ilc-cadernos.com/index.php/cadernos/article/ view/384/416. Acesso em: 03 set. 2019.

LISPECTOR, Clarice. Todos os contos. Rio de Janeiro: Rocco, 2016.

MUZART, Zahidé. L. (Org). Escritoras brasileiras do século XIX. Florianópolis: Mulheres, v. 3, 1999.

PONTIERI, Regina. Clarice Lispector - Uma poética do olhar. Cotia: Ateliê Editorial, 1999.

RIBEIRO, João. Prologo. In: SILVA, Francisca Julia da. Marmores. São Paulo: Horacio Belfort Sabino, p. 7-31, 1895. Disponível em: https://digital.bbm.usp. br/view/?45000008951\#page/34/mode/2up. Acesso em: 05 mar. 2021. RICH, Adrienne. Quando da morte acordarmos: a escrita como re-visão. In: BRANDÃO, Izabel; CAVALCANTI, Ildney; COSTA, Claudia de Lima e LIMA, Ana Cecília (Orgs.). Traduções da cultura. Perspectivas críticas feministas (1970-2010). Florianópolis: Mulheres, 2017. 
WOOLF, Virginia. Um teto todo seu. Tradução de Vera Ribeiro. Rio de Janeiro: Nova Fronteira, 1985.

\section{Marcus Vinícius de Oliveira Mitre}

Mestrando na UFSC e Bolsista da Coordenação de Aperfeiçoamento de Pessoal/Programa de Demanda Social (CAPES/DS).

Integra o Núcleo Literatual - Estudos Feministas e Pós-Coloniais de Narrativas da Contemporaneidade.

Lattes: http://lattes.cnpq.br/6486536861601189

E-mail: marcusmitre@gmail.com

ORCID: https://orcid.org/0000-0002-6809-0861

\section{Rosana Cássia dos Santos}

Doutora em Literatura pela UFSC.

Professora associada na mesma universidade.

Bolsista de Produtividade em Pesquisa do Conselho Nacional de Desenvolvimento Científico e Tecnológico (CNPq) - Nível 2, atuando na Graduação em Letras e na Pós-Graduação em Literatura da UFSC.

Integra a Editoria de Artigos da Revista Estudos Feministas - REF, é coordenadora do Núcleo Literatual - Estudos Feministas e Pós-Coloniais de Narrativas da Contemporaneidade e integrante do GT da Anpoll A Mulher na Literatura.

Lattes: http://lattes.cnpq.br/2499019809837384

E-mail: rosanack@yahoo.com.br

ORCID: https://orcid.org/0000-0002-3950-8157 